\title{
Uma parábola acadêmica: a jangada de Robert W. Fogel
}

\author{
An academic parable: Robert W. Fogel's raft
}

\author{
Heitor Pinto de Moura Filho \\ heitormoura@yahoo.com.br \\ Presidente \\ Associação Biblioteca de Cultura \\ Rua Paulo César de Andrade, 450/101 - Laranjeiras \\ 22221-090 - Rio de Janeiro - RJ \\ Brasil
}

\section{Resumo}

O livro Time on the Cross: The Economics of American Negro Slavery, de Robert W. Fogel e Stanley L. Engerman, alcançou grande fama como revolucionária interpretação da escravidão norte-americana, embora, à época, tenha sido detalhadamente criticado por especialistas em história econômica quantitativa. Cremos que citá-lo por seu pioneirismo nos estudos quantitativos da escravidão tenha-se tornado um "meme" acadêmico que não espelha adequadamente as contundentes críticas sofridas pelo livro nos anos seguintes ao seu lançamento. Este texto relembra o lançamento do livro e os debates subsequentes, no contexto ideológico e metodológico da época, discutindo as críticas, com o objetivo de relativizar a contribuição desses autores em comparação com a dos demais estudiosos da escravidão.

\section{Palavras-chave}

Escravidão; História quantitativa; Historiografia norte-americana.

\begin{abstract}
The book Time on the Cross: The Economics of American Negro Slavery, by Robert W. Fogel and Stanley L. Engerman achieved great fame as a revolutionary interpretation of North American slavery, even though at the time it was criticized in detail by specialists in quantitative economic history. We believe that to quote it as a pioneering quantitative study of slavery has become an academic "meme", which does not adequately reflect the severe criticism suffered by the book during the years following its publication. This text looks back to the book's release and the subsequent debates in the ideological and methodological context of the time, also discussing its criticized flaws, with the aim of comparing the contribution of these authors with those of other scholars on slavery.
\end{abstract}

\section{Keywords}

Slavery; Quantitative history; American historiography.

Recebido em: 2/4/2013

Aprovado em: 19/7/2013

\footnotetext{
${ }^{*}$ Agradeço os pertinentes comentários de Ricardo Salles e Rafael Marquese, bem como dos pareceristas desta publicação, permanecendo, contudo, responsável pelas opiniões aqui expressas.
} 
O desmesurado volume de informação disponível hoje em dia não garante que as novas gerações "estejam informadas". Até entre historiadores, pessoas portanto focadas em extrair informação do passado, vemos a repetição de "memes acadêmicos" que nem sempre espelham adequadamente o que ocorreu e, mais comumente, reforçam versões tendenciosas da história. Cremos que um desses memes ${ }^{1}$ recorrentes seja o papel do livro Time on the Cross: The Economics of American Negro Slavery, de Robert W. Fogel e Stanley L. Engerman (que abreviaremos como "TOTC" e "F\&E"), nos estudos sobre a escravidão norte-americana e, por extensão, sobre escravidão em geral.

TOTC foi publicado em 1974 e, com ele, F\&E alcançaram um feito inédito e, possivelmente, irreprodutível. Com um livro amplamente louvado (pela grande mídia e parte da comunidade acadêmica), mas também criticado em profundidade (por especialistas em história quantitativa da escravidão) por afirmar mais do que demonstra, por alardear o que não entrega, por sonegar fontes, por empregar dados pouquíssimo representativos para validar afirmações taxativas e gerais, por apresentar argumentos sistematicamente viesados em defesa das opiniões dos autores e, além disto tudo, por conter inúmeros erros de raciocínio e de cálculos - ou seja, com tudo o que é explicitamente banido da prática acadêmica - estes autores tornaram-se conhecidos do grande público como importantes historiadores econômicos; foram aclamados por (boa parte de) seus pares como respeitados, embora polêmicos e iconoclásticos, colegas; acumularam a fama de terem feito avançar o conhecimento historiográfico sobre a escravidão norte-americana; e até hoje gozam da recompensa máxima da academia que é serem repetidamente citados quando se escreve sobre economia da escravidão. Este descompasso pode ser parcialmente explicado pelo fato de, depois de TOTC, Fogel ter continuado a comandar pesquisas sobre escravidão, desenvolvendo com sucesso sua trajetória de "superstar" acadêmico. Na década e meia que se seguiu, publicou outros quatro volumes - intitulados Without Consent or Contract -, num total de cerca de 2.100 páginas, onde repetiu, mas também reviu e ampliou argumentos lançados em TOTC, agora agregando a participação de 2 coeditores, 17 coautores aos textos do volume principal e, nos dois volumes de "textos técnicos" anexos, mais 34 contribuições de alguns desses mesmos coautores, junto com outros 16, num total de 36 pesquisadores (FOGEL 1989; FOGEL; ENGERMAN 1992a; 1992b). Nesses livros, alguns temas polêmicos de TOTC foram atenuados, muitos novos dados foram analisados, mas os principais argumentos foram reafirmados. Em 1993, Fogel recebeu o chamado Prêmio Nobel de Economia.

Os presentes comentários visam a reavivar as críticas levantadas no que foi intitulado pelo próprio Fogel de "debates sobre escravidão", frequentemente desconhecidas (ou não mencionadas) pelos que citam o livro e seu principal autor.

Ao voltar recentemente a este volumoso debate, surpreendeu-nos a clareza e o vigor das críticas a TOTC. ${ }^{2}$ Surpresa ainda maior sobreveio ao percebemos

\footnotetext{
${ }^{1}$ Termo criado em 1976 por Richard Dawkins. É, para a memória, o análogo do gene na genética: a unidade de informação mínima que se multiplica de cérebro em cérebro ou de mídia em mídia.

2 Por exemplo, as resenhas de Haskell (1975), Supple (1977) e Fenoaltea (1981); o simpósio dedicado à
} 
que aquelas críticas - arrasadoras, do nosso ponto de vista - se diluíram entre as múltiplas polêmicas midiáticas que se seguiram à publicação de TOTC, de fato desaparecendo das reputações de $F \& E$, em especial depois da publicação de Without Consent or Contract.

Apesar dessas extensas polêmicas a seu redor, vemos TOTC ser citado quase unicamente pela repetição das afirmações de seus próprios autores, que, como indicamos a seguir, foram exageradamente autocondescendentes e autoenaltecedores ao anunciarem os significados de seus próprios resultados, ao repetirem a quem estariam se contrapondo e ao insistirem nas conclusões pelas quais esperavam ser avaliados por contemporâneos e pela posteridade. ${ }^{3}$ Por fim, ficamos admirados mais uma vez ao verificar como esta obra e seus autores se beneficiam de uma reluzente reputação "oficial", que ultrapassou as contundentes críticas de que foi alvo, seja aquelas que os autores desconsideraram, seja aquelas que responderam mas, na opinião de muitos historiadores, de fato não contestaram.

\section{Antecedentes}

TOTC foi publicado numa época em que os temas escravidão e racismo vinham sofrendo revisão em diversas frentes, na esteira da difusão de uma ideologia igualitária, propalada pelos Estados Unidos durante a guerra de 19391945, em oposição à ideologia racista do nacional-socialismo. Em torno desses temas, a sociedade norte-americana fartava-se de pontos sensíveis, entre eles o ainda regionalmente hegemônico racismo sulista e, no ambiente acadêmico, as explicações historiográficas sobre as causas da Guerra da Secessão e sobre o significado da escravidão para os estados sulistas, bem como reavaliações da escravidão em geral na história dos Estados Unidos. O contraste entre a ideologia igualitária e as práticas racistas norte-americanas, seja no exército vencedor (onde os batalhões de negros eram mantidos segregados), seja no cotidiano dos estados do Sul, seja ainda nos livros-textos de história, alimentou uma onda de revisões historiográficas. ${ }^{4}$

Um segundo contexto antecedente de importância fundamental para toda a polêmica que se seguiu situa-se na própria historiografia. Trata-se da aplicação a temas históricos do raciocínio metodológico e das práticas de "testes empíricos", quantitativos, desenvolvidos pela teoria econômica neoclássica. Esta outra "onda" acadêmica trouxe suas próprias polêmicas, que opuseram pesquisadores com formação em economia àqueles com formação em história, métodos quantitativos à historiografia "tradicional", uma epistemologia reputada "científica" às "ideológicas"

\footnotetext{
discussão de TOTC (WALTON 1975); e especialmente as críticas de David, Gutman, Sutch, Temin e Wright, com introdução de Stampp (DAVID; GUTMAN et al. 1976), além da obra de Gutman (1975a).

3 "O primeiro volume [de TOTC] é escrito num estilo direto, declaratório, que consegue incrível força argumentativa por deixar de lado as tediosas tarefas de qualificação e comprovação [...] acumula desprezo pelas interpretações anteriores, em especial as de Kenneth Stampp de Berkeley [...]. O segundo volume é efetivamente cheio de tabelas, equações e crípticas descrições de procedimentos, mas de fato não comprova a estória relatada tão simplesmente no primeiro volume" (HASKELL 1975). Todas as traduções são nossas.

${ }^{4}$ Esse contexto é descrito pelo próprio Fogel $(2003$, p. $1-3)$, que cita Kenneth Stampp $(1952 ; 1956)$ como o historiador que inicia esta revisão pós-1945. Também devemos acrescentar como decisivos nesta revisão: Gunnar Myrdal (1944), Eric Williams (1944) e Frank Tannenbaum (1947).
} 
ou "metafísicas", além de muitas oposições multilaterais e inconciliáveis entre diversas escolas dentro das ciências sociais e da história. Vale lembrar que a abordagem metodológica autoentitulada de "cliometria" por Fogel se compõe de dois pilares: por um lado, o uso de dados e de técnicas quantitativas e, por outro, dos conceitos da teoria econômica neoclássica, essencialmente estáticos e baseados em hipóteses ceteris paribus, quase sempre irreais em situações históricas. Ao insistir nos trunfos científicos do "quantitativismo", Fogel tornava esta a característica definidora da nova escola. Subsidiariamente - no que só podemos considerar como uma agenda oculta - Fogel conseguiu embutir, como passageiro clandestino na característica "quantitativo", todo o arcabouço da teoria econômica neoclássica, que, apesar de intrínseco a sua abordagem, raramente vinha explicitado. ${ }^{5}$ Assim, o epíteto cliométrico passou a designar, usualmente sem maiores especificidades, qualquer estudo quantitativo em história, o que contribuiu para transmitir ao grande público - e mesmo para os ambientes acadêmicos mais distantes da história econômica - uma ideia de nítida oposição entre dois campos, onde os "cliometristas", quantitativistas e (portanto) científicos, opunham-se aos historiadores "tradicionais", não quantitativos e (portanto) ideológicos e avessos ao "método científico". ${ }^{6}$

Robert Fogel foi um dos pioneiros da cliometria com sua tese onde "comprovava" a pouca importância das estradas de ferro para a economia norte-americana no século XIX através da construção hipotética de uma economia sem estradas de ferro, imaginada existir 60 anos após a real introdução das ferrovias. Embora seu método contrafactual tenha desencadeado relevante discussão sobre causalidade histórica, sua conclusão quanto às estradas de ferro foi bastante contestada dentro da própria grei cliométrica. ${ }^{7}$ Assumindo a polêmica e como forma explícita de se distinguir do restante dos pesquisadores que se dedicam à história, Fogel regularmente classifica seu método com o termo "cliometria", cujo début, segundo ele, teria ocorrido em 1956:

A cliometria anunciou seu nascimento numa conferência em Williamstown em 1956 [...] O ponto alto da conferência foi a apresentação por dois jovens econometristas de Harvard, com forte interesses históricos, Alfred H. Conrad e John R. Meyer, que surpreenderam a conferência com um trabalho chamado "A economia da escravidão no Sul do Pré-Guerra". Contradizendo o conhecimento estabelecido, argumentavam que, longe de ter sido um desastre econômico, as plantações escravistas do Sul ante-bellum haviam sido altamente lucrativas (FOGEL 1996, p. 11).

\footnotetext{
5 O simples uso de dados e métodos quantitativos não era então novidade, pois a historiografia francesa (tanto a vinculada aos Annales, quanto aquela focada na reconstituição macroeconômica), já os utilizava em abundância há quase meio século e dentro de perspectivas epistemológicas bem distintas. Por um lado, enfatizavam menos o aspecto quantitativo em si do que o aspecto serial dos dados e de seu tratamento. Por outro, passavam ao largo das teorias de mercados, fundadas na conceituação de um "equilíbrio" entre oferta e demanda de produtos, trabalho ou capital.

${ }^{6} \mathrm{O}$ assunto vem sendo amplamente resenhado e debatido há 6 décadas. Para uma medida de seus contornos: Claudia Goldin resenha os trabalhos de Fogel e North (GOLDIN 1995); Claude Diebolt discute a abrangência de temas e problemas epistemológicos em torno da cliometria (DIEBOLT 2012); Avner Greif avalia as mudanças nas relações entre cliometria e teoria econômica neoclássica (GREIF 1997); Angela M. Rojas descreve a evolução da área de 1957 a 2005, analisando os programas científicos dos cliometristas e das instituições onde pesquisam (ROJAS 2006).

7 Haskell (1975) cita as críticas de David, Desai, Lebergott, Scheiber, McClelland e Gerschenkron. Para uma resenha detalhada da obra de Fogel, ver Davis (2000).
} 
Nesse ambiente intelectual, Conrad e Meyer haviam reunido dois assuntos polêmicos - escravidão e métodos quantitativos em história - num único texto, ${ }^{8}$ onde analisavam a lucratividade da escravidão a partir de sua "racionalidade econômica", ou seja, com base numa argumentação quantitativa onde procuraram calcular como um senhor de escravo seria suposto tomar uma decisão "racional", ao cotejar os custos de comprar e manter seus escravos com a receita que viria a auferir ao longo da futura vida útil desses "bens de capital". Atribuíram a seu texto o objetivo explícito de contribuir para a controvérsia entre historiadores tradicionais e os revisionistas sobre a estagnação ou lucratividade do sistema escravista no Sul dos EUA às vésperas da Guerra Civil.

O longo debate resultante logo extrapolou os contidos limites da comunidade de economistas. Embora Fogel tenha avaliado que "foi o desafio metodológico posto pelo [texto de Conrad e Meyer] mais do que a essência do problema [da lucratividade da escravidão] que inicialmente chamou a atenção da maioria dos cliometristas" (FOGEL 2003), o debate ganhou muito de seu ímpeto polêmico por seus implícitos aspectos morais e políticos, de aparentemente "defender" a escravidão ao mostrá-la lucrativa e não moribunda, o que - além do mais - se confundia facilmente com a simples "defesa da escravidão".

Nos anos que se seguiram, diversos estudos adotaram por tema os problemas da escravidão, abordando-os com metodologia da teoria econômica. ${ }^{9}$ Em 1972, Engerman e Genovese, com o apoio institucional de Fogel, organizaram um seminário que pretendia reunir diversas abordagens quantitativas ao estudo da escravidão, onde alguns dos futuros críticos de TOTC já apresentariam pesquisas sobre os temas polêmicos. ${ }^{10}$ Foi exatamente nessa década de 1963 a 1973 que os estudos "cliométricos" avançaram com firmeza no establishment acadêmico norte-americano, tornando-se praticamente o padrão no setor, como demonstrou Whaples, ao calcular o percentual de trabalhos quantitativos no total de artigo publicados pelo Journal of Economic History (Figura 1).

\footnotetext{
${ }^{8}$ Segundo Conrad e Meyer (1964, p. IX), a conferência mencionada por Fogel teria de fato ocorrido em setembro de 1957 (e não 1956). O texto publicado no Journal of Political Economy (CONRAD; MEYER 1958), com duas críticas posteriores e suas respectivas respostas, foi reproduzido em CONRAD; MEYER 1964.

9 Alguns exemplos: Yasuba mostrou que o sistema escravista poderia se perpetuar com a criação lucrativa de escravos (YASUBA 1961); Evans Jr. estimou taxas de retorno sobre o capital em escravos no período 1830-60, reafirmando a viabilidade da escravidão (EVANS Jr 1962); E. Domar modelou razões econômicas para o surgimento e o desaparecimento da escravidão agrícola (DOMAR 1969), Bergstrom discutiu de forma matematizada a otimização do equilíbrio competitivo numa economia escravista (BERGSTROM 1971). Nos anos 1970, o cálculo da lucratividade da escravidão brasileira foi tema para estudos de Hélio Portocarrero de Castro, Pedro Carvalho de Mello e Robert W. Slenes. No presente trabalho, contudo, deixaremos de lado a discussão relativa à escravidão no Brasil.

10 Sutch analisou a "criação" de escravos e a expansão da escravidão para o Oeste (SUTCH 1975); Goldin procurou mostrar que o número de escravos urbanos diminuiu não por sua inviabilidade ou falta de demanda por eles nas cidades, mas porque o preço dos escravos na agricultura aumentou, retirando-os de ocupações urbanas (GOLDIN 1975).
} 
Figura 1 - Percentual de artigos quantitativos publicados no Journal of Economic History entre 1963 e 1973

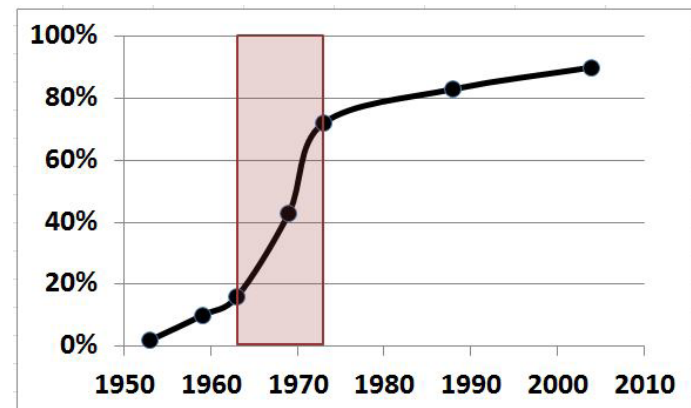

(WHAPLES 1991, p. 289-301).

\section{TOTC e sua divulgação}

Em 1971, F\&E publicaram uma coletânea de textos representativos da produção cliométrica na década anterior, onde já incluíam um texto intitulado "A economia da escravidão". Muito deste material seria logo reaproveitado em TOTC. Levantavam a questão da eficiência relativa do trabalho escravo. Ao ensaiarem um cálculo preliminar dessa eficiência, Fogel lembra ter-se espantado ao chegar a um melhor resultado para a agricultura escravista do que para a livre. Dedicaramse, então, durante alguns meses ao estudo do tema, mas só conseguiram "piorar" o problema, pois o trabalho escravo continuava mostrando-se mais eficiente do que o trabalho livre.

Neste ponto fizemos o que todos os economistas fazem quando têm um problema: solicitamos apoio para pesquisa à National Science Foundation (NSF). Esta bolsa e as várias que se seguiram permitiram que levássemos a cabo um aprofundado exame de todos os aspectos da escravidão, como uma instituição econômica, social e política (FOGEL 1996, p. 12).

O primeiro resultado público dessas pesquisas foi TOTC. Para realizar o extenso levantamento de dados sobre o qual se apoiou TOTC, F\&E lançaram mão de um exército acadêmico: 5 cliometristas com diferentes especializações, cerca de 25 estudantes de pós-graduação da Universidade de Chicago, cerca de 20 profissionais que leram todo o manuscrito em versão preliminar e 93 pessoas, incluindo conceituados historiadores econômicos e historiadores da escravidão que leram partes do manuscrito (GUTMAN 1975a, p. 2).

O livro foi publicado em duas partes, sendo a primeira explicitamente preparada "para o grande público", em edição econômica, com capa chamativa (onde era promovido como "um amplo reexame dos fundamentos econômicos da escravidão negra americana") e sem "detalhes acadêmicos", que foram relegados ao volume de "evidências e métodos", em edição mais cara. No tomo principal, o texto adota uma retórica afirmativa, sem os qualificativos nem os argumentos probatórios usuais da redação acadêmica. Como resume Weiss (2001), "[TOTC] foi escrito e produzido de modo a atrair uma quantidade anormalmente grande de atenção". Os próprios autores enfatizam esta intenção: 
"A reconstrução que surgiu [de suas pesquisas] encontra-se tão em desacordo com as crenças comuns e suas implicações são tão centrais à compreensão de problemas contemporâneos, que acreditamos que estas novas descobertas não devam mais ficar restritas às páginas de esotéricas revistas acadêmicas" (FOGEL; ENGERMAN 1989, p. 4).

Já no Prólogo de TOTC, F\&E listam um "decálogo" do que pretendem ser "algumas das principais correções à caracterização tradicional da economia escravista" que apresentam no restante do livro. Essas afirmações serão repetidas sistematicamente, quase como mantras, ao longo do texto: a escravidão não havia sido um sistema irracional, nem se encontrava moribunda às vésperas da Guerra Civil; a agricultura escravista não havia sido ineficiente se comparada à livre; o escravo não era preguiçoso; não havia incompatibilidade entre escravidão e indústria; a família escrava havia sido a unidade social básica da escravidão; a qualidade de vida material dos escravos se comparava favoravelmente com a de trabalhadores livres; os escravos recebiam cerca de $90 \%$ do valor de seu trabalho; e, por fim, a economia dos estados sulistas estava em franca expansão nas décadas anteriores a 1860. Considerando o contexto da época, quando ocorriam aguerridos debates sobre a participação dos negros na sociedade norte-americana, pode-se imaginar a estrepitosa repercussão midiática desse decálogo. ${ }^{11}$

TOTC teve seu lançamento programado como uma campanha de marketing de produto de consumo popular: ${ }^{12}$ sua primeira resenha apareceu, inabitualmente, no Wall Street Journal, seguida de outras, todas favoráveis, na grande imprensa (como Time, o New York Times e o Washington Post). Segundo Kolchin, "F\&E tornaram-se celebridades instantâneas, aparecendo em artigos e resenhas na imprensa popular e convidados a explicar suas descobertas ao público pelo rádio e em programas de entrevistas..." (KOLCHIN 1992, p. 491). Em talk shows com audiência nacional, Fogel repetia seu decálogo de "descobertas", insistindo no processo "científico", computadorizado, pelo qual os resultados foram obtidos. As "descobertas" tornavam-se especiais e únicas justamente por dependerem de esotéricas técnicas matematizadas e do (então) dispendioso tempo de computadores. ${ }^{13}$ Apesar desse pano de fundo, os temas de interesse das grandes mídias não eram nem as filigranas da pesquisa histórica e nem as discussões metodológicas. Desde logo, os debates fugiram aos cânones acadêmicos, assumindo tom emocional e colorido ideológico. Discutia-

\footnotetext{
${ }^{11}$ A resenha de Mildred Fierce, por exemplo, cita o decálogo verbatim e lança: "[...] vários aspectos de seus argumentos nos levam de volta [...] diretamente para a posição de muitos apologistas do século XIX ou início do século XX [...] com sua caracterização da escravidão como uma instituição benigna e flexível..." (FIERCE 1975, p. 91-92). Barry Supple resume assim o caráter radical da revisão proposta por F\&E: "Um livro que concluiu que a escravidão havia sido um instituição econômica lucrativa não porque os escravos eram explorados, mas exatamente porque eles não o eram [...] estava fadado a ter um impacto assaz retumbante" (SUPPLE 1977, p. 181).

12 Fierce avalia que: "[...] o que estamos presenciando é uma magistral promoção de marketing, cuidadosamente planejada, sem paralelo na história editorial das chamadas obras acadêmicas. Os editores e os autores são epítomes do axioma capitalista da 'maximização de lucros'" (FIERCE 1975, p. 89-90).

${ }_{13}$ As resenhas mais populares insistiram que "muitos de seus gráficos, equações e símbolos estão acima da compreensão da maioria dos historiadores". Comentou Gutman: "A mensagem era perfeitamente clara. Historiadores que não dispusessem desses instrumentos poderiam chafurdar por outros 100 anos em confusão subjetiva e nunca conseguirem avaliar ou rebater o trabalho dos cliometristas" (GUTMAN 1975a, p. 3).
} 
-se o "julgamento histórico" da escravidão e os autores justificavam-se de acusações de defender a escravidão, protegendo-se atrás do "método científico" propiciado pela cliometria. ${ }^{14}$ Ao final, no entanto, as questões de metodologia mostravam-se de pouco interesse para o público, diante dos virulentos debates sobre temas morais e ideológicos - em torno da escravidão e da "herança" da escravidão para os atuais afro-americanos - que foram o foco quase exclusivo da atenção geral. Esses debates de alta visibilidade tiveram como consequência desqualificar qualquer discussão tida por "técnica" como um assunto menor frente à importância dos problemas morais em discussão. Como algo implícito dessa oposição, concluía-se que, sendo os temas técnicos de fato irrelevantes para o grande público, também só poderiam ser irrelevantes as críticas técnicas lançadas contra TOTC.

\section{As críticas acadêmicas a TOTC}

Apesar da aclamação do grande público e de diversos setores acadêmicos, TOTC enfrentou intensas e numerosas críticas profissionais. Embora Fogel já fosse conhecido na comunidade acadêmica como defensor das técnicas quantitativas e dos métodos neoclássicos em história, tanto por sua polêmica tese contrafactual sobre as ferrovias, quanto por sua atuação como divulgador de pesquisas históricas com estes enfoques (inclusive fora dos temas econômicos), TOTC abriu novos debates e discussões. Podemos aferir a importância atribuída pelos especialistas em história econômica quantitativa à necessidade de se contraporem às declarações do livro pela rapidez e pelo número das críticas que se seguiram a sua publicação. Weiss relata: "Houve uma abundância de pesquisas, papers, edições especiais de revistas, coletâneas de artigos, monografias e sessões de conferência..." (WEISS 2001). TOTC saiu em maio de 1974. Já em setembro, eram publicados o artigo de David (1974) e a crítica de Haskell (1974). Em janeiro de 1975, Gutman publicava sua extensa resenha (de 175 páginas) (GUTMAN 1975b). Seguiam-se: David e Temin (1975) e Haskell (1975). O texto de Gutman, revisto e ampliado, foi publicado como livro ainda em 1975 (GUTMAN 1975a). Os artigos de David (Stanford), Gutman (CUNY), Sutch (Berkeley), Temin (MIT) e Wright (Michigan) foram reunidos no livro Reckoning with Slavery, publicado em 1976, com uma introdução do historiador tradicional (não quantitativista), Kenneth Stampp, que fora asperamente criticado por F\&E em TOTC. A abrangência, precisão e relevância das cuidadosas críticas desses seis autores, ao longo das 380 páginas do livro, apontam indesculpáveis falhas de TOTC. E, como bem observou Haskell, tais críticas não provinham de adversários da cliometria; eram os próprios especialistas em métodos quantitativos e na abordagem econômica neoclássica quem as assinavam - o que, por outro lado,

\footnotetext{
${ }_{14}$ Vale lembrar que, no final dos anos 1960 e na primeira metade dos anos 1970, escravidão era tema de múltiplas abordagens e polêmicas. Como exemplos, mencionamos os assuntos e autores a seguir: comparações internacionais (Freyre, Elkins, Tannenbaum, Harris, Brion Davis e Mintz); análise marxista (Genovese e Davis); publicações de relatos e biografias de escravos (Blassingame, Harlan, David Cronon e Douglass), textos de escritores negros (Barksdale e Kinnamon); história de negros livres e libertos (Morgan e Litwack). Começavam a ganhar importância os estudos focados na família negra, sob escravidão ou liberdade (Moynihan, Franklin Frazier, Genovese, Schweninger, Rawick e Gutman). Estudos focados no papel das mulheres, no entanto, só viriam a assumir importância maior nas décadas de 1980 e 1990 (Leslie, White, Stevenson, Frankel, Lerner e Forbes).
} 
seria de se esperar, dada a hermeticidade das técnicas e da apresentação da obra, insistentemente fora dos "protocolos" acadêmicos dos historiadores. ${ }^{15}$

Outra importante medida do ineditismo da polêmica em torno de TOTC foi o fato de terem sido organizados diversos encontros universitários exclusivamente para discutir o livro. O simpósio de maior repercussão, com a presença de uma centena de pesquisadores, entre eles destacados historiadores econômicos e cientistas sociais interessados em história, e dos próprios autores, ocorreu durante três dias, na Universidade de Rochester, em outubro de 1974, sob a organização "ecumênica" de Eugene Genovese e Stanley Engerman. ${ }^{16}$ Como bem notou Haskell, a discussão metodológica esperada por F\&E não chegou a acontecer, pois "TOTC, julgado sob suas próprias premissas, mostrou-se tão seriamente falho a ponto de não sustentar qualquer controvérsia mais profunda" (HASKELL 1975). F\&E procuraram responder às consistentes críticas à lógica, às premissas e ao padrão acadêmico do livro e, ao final, imprensados, optaram por qualificar o livro de "um relatório preliminar".17 Eugene Genovese, ao fechar o evento, viu-se impelido - com "luvas de pelica", supomos - a chamar TOTC de "um fracasso criativo"!

Como uma discussão, mesmo resumida, dos temas criticados extrapolaria, em muito, os limites de um único texto, ficaremos aqui com sua simples itemização, acompanhada de algumas citações de fontes.

Sobre a forma do livro, houve dois tipos de crítica: uma primeira quanto ao tom de sua redação, assertivo e sem as incertezas ou escrúpulos comuns à argumentação acadêmica ${ }^{18}$ e uma segunda quanto à incompleta comprovação de fontes ou mesmo à ausência de comprovação. ${ }^{19}$

Houve, ainda, críticas generalizadas ao tratamento dado por F\&E aos historiadores "tradicionais" e outros estudiosos da escravidão e da economia sulista, que foram caracterizados (muitos críticos preferiram dizer "caricaturados") por chavões, dos quais F\&E omitiram todas as qualificações e precauções argumentativas com as quais esses autores haviam apresentado

\footnotetext{
${ }_{15}$ F\&E fazem questão de agradecer, em TOTC, a diversos desses autores, com o caveat de que "Não se deve supor que aqueles cuja ajuda reconhecemos concordem necessariamente com nossos resultados. Alguns deles têm sido altamente críticos do encaminhamento geral de nossa pesquisa [...]" (FOGEL; ENGERMAN 1989 , p. 277).

16 Haskell (1975) cita a presença de: Kenneth Stampp, Stanley Elkins, David Brion Davis, Vann Woodward, Winthrop Jordan, Oscar Handlin, Albert Fishlow, Peter Laslett e Hartwell.

${ }_{17}$ A que David et al. responderam, explicitando o descompasso entre as afirmações em TOTC e esta desculpa inconvincente: "...[o livro] não foi publicamente apresentado nem publicamente recebido como mera especulação. TOTC se anuncia como o produto de descobertas de 'quase uma década e meia' de intensas e sofisticadas pesquisas por um grande grupo de estudiosos, a partir das quais 'as principais características da real operação da economia escravista estão agora claras'. Sem dúvida, qualquer obra histórica que faz tais afirmações merece nada menos do que ser levada a sério e julgada sobre seus próprios méritos" (DAVID; GUTMAN et al. 1976, p.VIII-IX).

18 Os próprios autores, em TOTC $2^{\circ} \mathrm{V}$., Apêndice A, concedem ter extrapolado os protocolos acadêmicos (FOGEL; ENGERMAN 1974, p. 4).

19 Sobre falhas na comprovação das fontes e do raciocínio: "Talvez a crítica acadêmica mais comum a F\&E seja sua omissão [...] em anotar seus argumentos de modo a permitir que seus leitores examinem facilmente suas fontes ou determinem a maneira como chegaram a suas conclusões. O texto nem oferece notas de rodapé nem citações numeradas ao suplemento. Consultar o suplemento ao ler o texto é sempre difícil, muitas vezes atordoante e por vezes fútil. [...] sua afirmação de só terem aceitado seus 'inacreditáveis' resultados depois de checarem e rechecarem seus dados não se sustenta pela leitura de suas fontes, que, de fato, empregaram displicentemente" (STAMPP 1976, p. 9-10). "Uma conclusão científica, mesmo que plausível ou ideologicamente palatável, só se torna científica se os métodos específicos empregados para se chegar a ela se conformam aos padrões estabelecidos na disciplina" (DAVID; GUTMAN et al. 1976, p.VII-VIII).
} 
suas interpretações. Aproveitando esta caracterização forçada de seus predecessores, F\&E inflaram suas "descobertas", atribuindo-se a autoria de argumentos e pioneirismo no uso de fontes já usuais na historiografia sobre escravidão. Quanto a isto, Stampp avalia que, do decálogo de "correções" de TOTC, os primeiros 4 itens "a maioria dos historiadores da economia sulista havia aceitado há muito tempo"; o sexto havia sido publicado por Starobin quatro anos antes de TOTC; "não conheço nenhum historiador que defenda o sétimo"; e o argumento central do décimo havia sido publicado por Easterlin 14 anos antes de TOTC. As três correções remanescentes (5, 8 e 9) seriam afirmações inéditas e, portanto, não pertencendo a qualquer "interpretação tradicional", não poderiam ser consideradas "correções". Concluiu, assim, que a "interpretação tradicional da escravidão" criada por F\&E não passava de um "judas" retórico a ser malhado ao longo do texto (STAMPP 1976, p. 12-13).

Gutman enumera 25 "erros essenciais" de TOTC, que cobrem praticamente todos os argumentos de F\&E sobre as motivações dos cativos para adaptar-se ao sistema escravista: castigos, prêmios, estrutura ocupacional urbana e rural, percentual de escravos em posições "gerenciais", mobilidade de escravos, unidades familiares e casamentos, idade ao primeiro filho, entre outros tópicos (GUTMAN 1975a, p. 8-11).

\section{A linha mestra de TOTC}

Haskell percebeu uma fraqueza intrínseca do método cliométrico quando aplicado à história, que transparece claramente em TOTC: apesar de sua precisão, as equações, para serem resolvidas, requerem parâmetros, cuja estimação deriva de dados históricos ou, à falta destes, de hipóteses sobre seus possíveis valores.

Embora a cliometria exija que estas e qualquer outra hipótese sejam tornadas explícitas, não fixa um limite para o número de hipóteses que possam ser feitas, ou quão alto podem ser empilhadas hipóteses contingentes, contanto que sejam explicitadas. [...] Embora TOTC não seja um exercício contrafactual, depende de uma cadeia de hipóteses e estimativas não menos ousada (HASKELL 1975).

Essa "pilha" de hipóteses alicerçam o tema central de TOTC, que, segundo Gutman, seriam "as realizações dos negros, sob adversidade". Com tais "realizações", os atuais afro-americanos poderiam orgulhar-se de seus antepassados. A "nova história econômica" desmontava a imagem do escravo submisso ou, no máximo, reativo, rebelde, colocando no seu lugar um "agente da ética de trabalho protestante".

Para construir seu argumento em torno deste tema, F\&E pretendem que, no sistema escravista norte-americano, havia incentivos para que os escravos trabalhassem com eficiência, incentivos estes tanto negativos (o castigo) quanto positivos (prêmios - em tempo livre, benesses ou dinheiro - e a possibilidade de uma "carreira" que levaria a funções mais prestigiosas - de trabalhador braçal a trabalhador doméstico, artesão e supervisor de campo). Este argumento seria 
comprovado por uma série de subargumentos relativos, entre outros aspectos, à vida em família, à qualidade da alimentação e da moradia oferecidas pelos senhores a seus escravos. Os escravos teriam internalizado este sistema tão bem que F\&E caracterizam os escravos como tendo adotado uma ética de trabalho protestante, ou seja, que trabalhavam e trabalhavam bem porque assim era de seu interesse (e, portanto, assim o desejavam). Eram mais eficientes porque davam maior esforço por hora de trabalho, obtendo, portanto, maior produto do que o trabalhador livre. Sendo assim, comprovava-se a maior eficiência da unidade produtiva baseada no trabalho escravo, o que demonstrava a consequente eficiência de toda a economia escravista e, por fim, a vitalidade da economia sulista às vésperas da Guerra Civil. Ao serem desmontados cada um dos vários subargumentos e afirmações, desmontava também a pilha de hipóteses criadas por F\&E, desfazendo-se todas as suas "correções" à historiografia da escravidão. O problema original - a lucratividade da unidade econômica escravista - transformava-se somente num elo, possivelmente verdadeiro, mas agora isolado, de uma longa cadeia de hipóteses no argumento de TOTC.

David e Temin apontam essa contraditória atitude diante do trabalho escravo como o que F\&E teriam visto como a maior "realização" do povo americano negro sob escravidão. E mais, que F\&E haviam, consequentemente, rejeitado tanto a imagem do escravo infantilizado e submisso (o chamado "sambo") quanto a necessidade (econômica) da rebeldia ao cativeiro, defendidos por tendências historiográficas opostas. Em TOTC, ambos senhores e escravos se mostram desumanizados, convertidos em meros agentes econômicos que só reagem aos incentivos e desincentivos oferecidos pelo mercado. ${ }^{20}$

\section{A blindagem de тотC}

Ao longo das quase quatro décadas desde os debates em torno de TOTC, podemos perceber uma combinação de movimentos que levaram ao que poderíamos qualificar como a "blindagem" de TOTC, isto é, sua transformação num marco acadêmico "acima do bem e do mal", que não haveria mais sentido discutir.

O primeiro desses movimentos foi, certamente, o vai-e-vem das polêmicas sobre o "decálogo" de TOTC, durante as quais, segundo Jean Heffer, "Fogel parece ter adotado posições mais moderadas" (HEFFER 1977, p. 825). Essa extensa e variada polêmica frequentou regularmente as revistas econômicas e históricas de língua inglesa durante as três décadas após a publicação de TOTC, com destaque para o tema da lucratividade e da eficiência (inclusive tecnológica) da unidade agrícola escravista.

O segundo (e talvez o mais importante movimento nesse sentido) foi a continuidade das pesquisas sobre os temas debatidos, sejam aquelas conduzidas pelo próprio Fogel, sejam as de diversos pesquisadores independentes. ${ }^{21}$ Fogel,

\footnotetext{
20 "Os senhores aparecem indistinguiveis de puros homens econômicos [...] [F\&E] consideram que também os escravos haviam aprendido a reagir a uma gama de incentivos econômicos..." David e Temin (1975) apud Gutman (1975a, p. 6).

${ }_{21}$ Olmstead e Rhode examinam a evolução da produtividade do trabalho escravo frente à introdução de diversas variedades de algodão (OLMSTEAD; RHODE 2007) e a diversas variáveis da colheita (OLMSTEAD; RHODE 2011); G. Wright analisa a economia algodoeira como motor da economia sulista (WRIGHT 1974;
} 
por seu lado, arregimentou um grande número de coautores e assistentes de pesquisa, buscou novas fontes históricas e procurou tornar a argumentação de TOTC "mais robusta", sobrepujando a exposição original com novos dados e análises. Essa nova fase da polêmica se consolidou com a publicação de Without Consent or Contract (WCC), onde Fogel, no entanto, continua contrastando seus "resultados" com as "interpretações tradicionais". Na avaliação de Kolchin:

O surgimento em 1974 de TOTC, por F\&E, acendeu uma enorme controvérsia histórica. [...] o cerne dessas revisões [em WCC] foi no sentido de baixar o tom da retórica e não de repudiar as posições básicas. Apesar de concessões menores aos críticos, de ajustes mais numerosos e refinamentos aos argumentos anteriores, WCC oferece uma reafirmação das interpretações apresentadas em TOTC (KOLCHIN 1992, p. 495).

Mais do que a ajuda de simples assistentes de pesquisa para levantamento de dados, como ocorreu para TOTC, Fogel angariou, em WCC, a colaboração efetiva de profissionais reconhecidos, de fato diluindo a responsabilidade pela produção de argumentos ao estruturar o livro em torno de verbetes e artigos com autorias independentes. Kolchin explicita que:

Mais uma vez, [Fogel] se protege das críticas históricas ao cooptar a maior parte da profissão: como TOTC, WCC contém uma lista excessiva de agradecimentos [...] a 26 estudantes, a 37 de quem aprendeu ao debater, a 19 que leram o manuscrito, a 56 que leram partes dele, a 7 editores e seus assistentes e, por fim, a Stanley Engerman [...] (KOLCHIN 1992, p. 495).

Cremos que outro movimento fundamental (e em grande medida consequência dos próprios debates sobre TOTC), que também serviu como atenuante das polêmicas, foi o surgimento de novas áreas de estudos em torno da antropometria, nas quais medições de peso e altura passaram a servir como indicadores, essencialmente quantitativos, para níveis de nutrição e de qualidade de vida, conceitos de difícil aferição em si. O próprio Fogel abraçou o tema, enveredando pelo estudo da correlação entre o desenvolvimento econômico e o desenvolvimento corporal (FOGEL 2004).

Associado a estes vários movimentos diluidores das polêmicas, devemos reconhecer o mérito pessoal de F\&E, que, apesar da onda de críticas especializadas, por vezes ásperas, que sofreram, mantiveram relações profissionais e até cordiais com muitos de seus críticos, frequentemente colegas de departamento, coparticipantes em simpósios ou coautores em coletâneas sobre história econômica. Embora isto não tenha reduzido ou evitado críticas, certamente trouxe uma medida de civilidade e de propósito científico à discussão (pelo menos a que tratou dos aspectos mais técnicos do debate). Fogel confessou ter sido esta uma época dura, como podemos avaliar dos comentários de Peter Kolchin:

1975; 1978); Grabowski e Pasurka criam modelo para analisar as eficiências tecnológicas relativas da unidade escravista e não escravista (GRABOWSKI; PASURKA 1989); e Hummel (2001) argui a lucratividade da escravidão junto com sua ineficiência social. 
Embora alguns dos ataques foram mal humorados e exagerados e só produziram revisões menores das estatísticas de Fogel e Engerman, as críticas mais fundamentais a sua abordagem histórica básica deixaram TOTC com poucos defensores entre os historiadores profissionais. Poucos anos após sua publicação, a visão dominante sobre o livro havia se tornado de condescendência irônica: [...] tratava-se de uma obra ousada, mas agora desacreditada, que acrescentava pouco ao importante fluxo de revisionismo da escravidão nos anos [19]70 (KOLCHIN 1992, p. 492).

É importante notarmos que - talvez fora do comportamento comumente esperado em situações como essas - vários dos críticos mais veementes de F\&E (Gutman, Wright, Sutch e Temin) haviam recebido agradecimentos desses autores em TOTC. F\&E dedicam um parágrafo especial ao agradecimento a K. Stampp, que Ihes ofereceu detalhados comentários, "[...] ajudando a fortalecer nossos argumentos, mesmo quando se contrapunham com seu trabalho. Ao agir assim, estabeleceu um padrão acadêmico que nos esforçaremos a seguir, quando for nossa vez de enfrentar a crítica de nossos colegas" (FOGEL; ENGERMAN 1989, p. 278).

Os críticos, por sua vez, mostraram-se agradecidos a eles por seu apoio a suas próprias pesquisas, demonstrando seu respeito intelectual por estes pesquisadores. Herbert Gutman escreveu no Prefácio a seu Slavery and the Numbers Game:

F\&E são antigos colegas. Poucas pessoas foram mais importantes para meu próprio trabalho e mais generosas com seu tempo do que Stanley Engerman. Sinto-me endividado a ele. Não obstante, como as páginas que se seguem deixam repetidamente claro, estou convencido de que TOTC é uma obra profundamente falha (GUTMAN 1975a, p.VIII).

Gavin Wright, outro autor de duras críticas a TOTC (WRIGHT 1976), escreveu, pouco depois, em 1978, no seu livro The Political Economy of the Cotton South, o seguinte cortês reconhecimento a Fogel:

Este livro não [...] leva adiante o debate com TOTC de Robert W. Fogel e Stanley Engerman, um livro que aborda muitos temas que não tocamos aqui. Nosso livro deve muito ao trabalho desses dois estudiosos e às discussões e correspondência com eles durante vários anos, mesmo que, ao final, seu ponto de vista seja bem diferente (WRIGHT 1978, p. 6).

O conjunto de autores que mais se dedicaram para reunir de forma concatenada as críticas a TOTC, David, Gutman, Sutch, Temin e Wright, também fizeram questão de agradecer coletivamente a F\&E:

Não consideramos necessário reiterar agradecimentos anteriores, salvo um: Stanley Engerman e Robert Fogel generosamente responderam a numerosas perguntas e ofereceram dados brutos, que facilitaram em grande medida parte do trabalho sobre que se apoiam os capítulos adiante (DAVID; GUTMAN et al. 1976, p. X).

Esses múltiplos agradecimentos e demonstrações de respeito acadêmico transparecem também na declaração desses autores de que não viam o livro como uma "polêmica sobre a experiência afro-americana de escravidão" e, sim, 
como "uma contribuição científica à escrita da história americana em geral e da história da sociedade sulista ante-bellum em particular".

Sem dúvida, trata-se de exemplos, de parte a parte, a serem seguidos.

\section{A "jangada" de Robert Fogel}

Talvez caiba insistir, por fim, no dever de ofício do historiador de analisar criticamente as fontes, seja pessoalmente, seja pela intermediação dos que o fizeram, de modo a transmitir a seu leitor a mesma segurança que tiver adquirido sobre sua adequação aos argumentos em pauta. Perguntará o aluno interessado: "Mas como saberei que este historiador efetivamente as analisou?" Como quase tudo em história, nunca poderemos ter certeza absoluta disso, mas, seguindo os "protocolos" historiográficos, poderemos aumentar nossa confiança nas fontes e no historiador que afirma tê-las analisado. No caso de TOTC, no entanto, quem seguiu à risca os protocolos historiográficos e científicos não foram os autores e, sim, seus críticos. E justamente, ao refazerem o percurso que F\&E haviam citado como as pesquisas geradoras de TOTC, estes críticos trouxeram à tona inúmeros problemas. Contra tudo o que se espera de um texto acadêmico de primeira linha, F\&E valeram-se das aparências de protocolos acadêmicos, porém expuseram dados e conclusões apontadas, já na época, como absolutamente fora de qualquer padrão acadêmico de exposição e argumentação. A precisão técnica de tais críticas e a quantidade em que foram trazidas tornam incontroversa a acachapante sentença de que a pesquisa, a construção e a redação de TOTC fugiram insistentemente às práticas mínimas do ramo. Feita esta constatação, cremos que qualquer posterior referência ou citação ao livro deveria se fazer acompanhar dos devidos caveats, para evitar que os leitores destas referências ou citações também sejam iludidos pelas aparências e implicitamente aceitem a totalidade do conteúdo a que remetem. Não pode ser esquecido, consequentemente, que TOTC é uma obra atravessada por falhas desclassificantes: informações erradas, erros de cálculos, omissão de fontes, distorções de amostragem, retórica argumentativa tendenciosa, entre outros problemas que procuramos relembrar neste artigo.

Assim, se não somos capazes de explicar, pelo conteúdo de TOTC, sua repercussão na época e sua continuada reputação, só nos resta buscar uma explicação sociológica, na qual o livro apareceria mais como símbolo do que como obra acadêmica de fato. Apesar de suas falhas, não há como negar que TOTC tenha consolidado uma mudança de paradigma para a historiografia da escravidão, tanto por seus métodos quanto em sua epistemologia. Nem há que discutir, tampouco, que a publicação de TOTC tenha constituído um pico nos debates sobre escravidão.

Confrontados com esta antinomia, ocorre-nos uma parábola: F\&E teriam criado, com TOTC, uma "jangada acadêmica", que pode ser envolvida, afundada, virada e revirada, mas que sempre volta à tona - incólume, apesar de molhada - como se nada acontecera. Só tal "jangada" poderia enfrentar críticas tão claras e contundentes, que, por muito menos, reprovariam qualquer candidato a título ou a cargo acadêmico, conseguindo isolá-las em esotéricos debates 
entre especialistas, enquanto o público, as instituições financiadoras oficiais e mesmo a comunidade acadêmica em geral, fora daqueles especialistas, se contentavam com as afirmações originais dos autores e com os emblemáticos rótulos enaltecedores que extraíam dessas afirmações.

Esta "jangada" precisou ser construída, o que exigiu, antes de mais nada, que os autores se posicionassem favoravelmente junto a financiadores de pesquisas, junto às hierarquias universitárias e, claramente, junto a colegas e potenciais críticos. Além deste bem-sucedido posicionamento político, F\&E conseguiram feito pouco comum que foi serem ouvidos e apreciados pelo grande público. Mesmo tachados de "polêmicos" e "iconoclásticos", lograram obter o qualificativo bem mais importante, de "relevantes".

Vale lembrar que em nenhum momento depois da "acareação de Rochester" os autores concederam derrota que não fosse em pontos menores ou "detalhes de pesquisa, a serem futuramente aperfeiçoados". Em contrapartida, tampouco em nenhum momento deixaram de louvar o profissionalismo dos críticos e de agradecer suas críticas.

Ao aluno que, tendo lido este relato, pense em dedicar-se menos aos tediosos protocolos da historiografia e mais à política acadêmica, lembramos que F\&E estudaram e se estabeleceram profissionalmente numa época quando transcorria mudança única nas relações raciais norte-americanas. E que, por formação (aliás longa e trabalhosa), estavam posicionados nas hostes metodológicas que se expandiam naquele momento histórico e que lograram se impor no mundo acadêmico das décadas seguintes. Nenhum desses contextos e eventos se repetirá. Além do mais, como insistem os economistas de Chicago, o atual mercado acadêmico - bem mais competitivo - certamente punirá quem aparentar pouco profissionalismo, preferindo recompensar seus concorrentes mais esforçados.

\section{Referências bibliográficas}

BERGSTROM, Ted. On the Existence and Optimality of Competitive Equilibrium for a Slave Economy. The Review of Economic Studies, 1971, v. 38, n. 1, p. 23-36.

CONRAD, Alfred H.; MEYER, John R. The Economics of Slavery in the Ante Bellum South. The Journal of Political Economy, 1958, v.66, n.2, p.95-130.

The Economics of Slavery and Other Studies in Econometric History. Chicago: Aldine Publishing Company, 1964.

DAVID, Paul A. Slavery: The Progressive Institution. Journal of Economic History, 1974, v.34, p.739-783.

; GUTMAN, Herbert G., et al. Reckoning with Slavery: a Critical Study

in the Quantitative History of American Negro Slavery. New York: Oxford University Press, 1976.

; TEMIN, Peter. Capitalist Masters, Bourgeois Slaves. Journal of Interdisciplinary History, 1975, v.5, p.445-457. 
DAVIS, Lance. Review of Robert W. Fogel, Railroads and American Economic Growth: Essays in Econometric History. EH.Net Economic History Services, 2000. Disponível em: http://eh.net/bookreviews/library/ davis. Acesso em 06 jul. 2007.

DIEBOLT, Claude. The Cliometric Voice. Association Française de Cliométrie - Working Papers, 2012, v.12, n.9.

DOMAR, Evsey D. The Causes of Slavery: A Hypothesis. Working Papers Dept. of Economics - MIT, 1969, v.42, n.25.

EVANS Jr, Robert. The Economics of American Negro Slavery in NBER Aspects of Labor Economics. Washington, DC: Princeton University Press, 1962, p.185-256.

FENOALTEA, Stefano. The Slavery Debate: A Note from the Sidelines. Explorations in Economic History, 1981, v.18, p. 304-308.

FIERCE, Mildred. Plus ça change plus c'est la même chose. Phylon, 1975, v.36, n.1, p. 89-93.

FOGEL, Robert William, Ed. Without Consent or Contract. The Rise and Fall of American Slavery. New York: W.W.Norton \& Co., 1989.

A Life of Learning. American Council of Learned Societies Occasional Paper, 1996, n.34.

. The Slavery debates, 1952-1990: a Retrospective. Baton RougeLa: Louisiana State University Press, 2003.

The Escape from Hunger and Premature Death, 1700-2100.

Cambridge: Cambridge University Press, 2004.

. ENGERMAN, Stanley L. Time on the Cross: Evidence and Methods. A

Supplement. Boston: Little Brown \& Co, 1974.

. Time on the Cross: the Economics of American Negro Slavery. New York: W.W.Norton \& Co, 1989 [1974].

(eds.). Without Consent or Contract: the Rise and Fall of American Slavery. Conditions of Slave Life and the Transition to Freedom: Technical Papers. Vol.2. New York: W.W.Norton \& Co, 1992a.

(eds.). Without Consent or Contract. The Rise and Fall of American Slavery. Markets and Production. Technical Papers Vol.1. New York: W.W.Norton \& Co, 1992 b.

GOLDIN, Claudia. Cliometrics and the Nobel. The Journal of Economic Perspectives, 1995, v.2, p.191-208.

A Model to Explain the Relative Decline of Urban Slavery: Empirical Results In: ENGERMAN, S.L.; E.D.GENOVESE (eds.). Race and Slavery in the Western Hemisphere: Quantitative Studies. Princeton-NJ: Princeton University Press, 1975, p.427-450. 
GRABOWSKI, Richard; PASURKA, Carl. The Relative Technical Efficiency of Slave and Non-Slave Farms in Southern Agriculture. Eastern Economic Journal, 1989, v.15, n.3, p.245-258.

GREIF, Avner. Cliometrics After 40 Years. AEA Papers and Proceedings, 1997, v.87, n.2, p.400-403.

GUTMAN, Herbert G. Slavery and the Numbers Game: a Critique of Time on the Cross. Chicago: University of Illinois Press, 1975a.

. The World Two Cliometricians Made: A Review-Essay of $F+E=T / C$ Journal of Negro History, 1975b, v.60, p.53-227.

HASKELL, Thomas L. Were Slaves More Efficient? Some Doubts About Time on the Cross. New York Review of Books (19-set-1974), p.38-42.

. The True \& Tragical History of 'Time on the Cross'. The New York Review of Books, 1975, v.22, n.15.

HEFFER, Jean Une histoire scientifique: la nouvelle histoire économique. Annales. Économies, Sociétés, Civilisations, 1977, v.32, n.4, p.824842.

HUMMEL, Jeffrey Rogers. Deadweight Loss and the American Civil War: the Political Economy of Slavery, Secession, and Emancipation. Austin-TX: University of Texas, Austin. Ph.D. Graduate School, 2001.

KOLCHIN, Peter. More Time on the Cross? An Evaluation of Robert William Fogel's Without Consent or Contract. The Journal of Southern History, 1992, v.58, n.3, p.491-502.

MYRDAL, Gunnar. An American Dilemma. The Negro Problem and Modern Democracy. New York: Harper \& Bros, 1944.

OLMSTEAD, Alan L.; RHODE, Paul W. "Wait a Cotton Pickin' Minute!" A New View of Slave Productivity. Private working paper, 2007, n.48

. Slave Productivity in Cotton Production by Gender, Age, Season, and Scale. Private working paper, 2011, n.20.

ROJAS, Angela Milena. Cliometrics: a market account of a scientific community (1957-2005). Borradores - Centro de Investigaciones Económicas Universidad de Antioquia, 2006, v.16, n.54.

STAMPP, Kenneth M. The Historian and Southern Negro Slavery. American Historical Review, 1952, v.57, p.618-624.

The Peculiar Institution: Slavery in the Ante-Bellum South. New York: Alfred A. Knopf, 1956.

. Introduction. A Humanistic Perspective in DAVID, P.A. et.al. Reckoning with Slavery. New York: Oxford University Press, 1976, p.1-30.

SUPPLE, Barry. Reckoning with Slavery. A Critical Study in the Quantitative History of American Negro Slavery by P.A.David; H.G.Gutman; R.Sutch; 
P.Temin; G.Wright. The Economic Journal , 1977, v.87, n.345, p.181183.

SUTCH, Richard. The Breeding of Slaves for Sale and the Westward Expansion of Slavery, 1850-1860. In: ENGERMAN, S.L.; E.D.GENOVESE (eds.). Race and Slavery in the Western Hemisphere: Quantitative Studies. Princeton, NJ: Princeton University Press, 1975, p.173-210.

TANNENBAUM, Frank. Slave and Citizen: the Negro in the Americas. New York: A. A. Knopf, 1947.

WALTON, G.M., Ed. A Symposium on Time on the Cross. Explorations in Economic History, 1975.

WEISS, Thomas. Review Essay of Time on the Cross: The Economics of American Negro Slavery. EH.Net Economic History Services, 2001. Disponível em: http://eh.net/book_reviews/time-cross-economics-american-negroslavery. Acesso em 02 mar. 2013.

WHAPLES, R. A Quantitative History of the JEH and the Cliometric Revolution, JEHistory, 51, 1991, p. 289-301.

WILLIAMS, Eric. Capitalism and Slavery. Chapel Hill: The University of North Carolina Press, 1944.

WRIGHT, Gavin. Cotton Competition and the Post-Bellum Recovery of the American South. Journal of Economic History, 1974, v. 34.

. Slavery and the Cotton Boom. Explorations in Economic History, 1975, v.12, p. 439-451.

Prosperity, Progress, and American Slavery. In: DAVID, Paul A. et al. Reckoning with Slavery. New York: Oxford University Press, 1976, p.302-336.

The Political Economy of the Cotton South. New York: W.W. Norton \& Co, 1978.

YASUBA, Y. The Profitability and Viability of Plantation Slavery in the United States. The Economic Studies Quarterly, 1961, v.12, p. 60-67. 